\title{
The role of manganese superoxide dismutase in skin aging
}

\author{
Nicolai Treiber, ${ }^{1}$ Pallab Maity, ${ }_{1}$ Karmveer Singh, ${ }^{1}$ Florentina Ferchiu, ${ }^{1}$ Meinhard Wlaschek ${ }^{1}$ and Karin Scharffetter-Kochanek ${ }^{1,2 . *}$ \\ 'Department of Dermatology and Allergic Diseases; University of Ulm; Ulm, Germany; ${ }^{2}$ Competence Center for Gerontology and Aging Research; Ulm, Germany
}

Keywords: skin aging, oxidative stress, MnSOD, SOD2, ROS

The free radical theory of aging postulates that the production of mitochondrial reactive oxygen species is the major determinant of aging and lifespan. The skin represents an excellent and accessible model organ to study aging that is characterized by atrophy, wrinkle formation, reduced tensile strength and impaired wound healing. Oxidative stress as a consequence of an imbalance in prooxidants and antioxidants with increased ROS concentrations has been demonstrated in the aged skin in vitro and in vivo, suggesting the important role of the antioxidant balance. Here we will summarize recent data on the role of the mitochondrial superoxide dismutase 2 in skin aging.

\section{Introduction}

The free radical theory of aging, published in 1956 by Denham Harman, ${ }^{1}$ postulates that reactive oxygen species, normally produced in organisms with cellular constituents, initiate changes associated with aging. During the last couple of years, the importance of the antioxidant system in aerobic cells, which was evolved to protect against oxidative injury, has been acknowledged. The imbalance of antioxidant enzymes, the role of reactive oxygen species as important physiological regulators of intracellular signaling pathways as well as the increased oxidative stress in senescence and aging have been a matter of increasing interest. ${ }^{1-6}$

Among the multilayered and interdependent antioxidant system, which consists of non-enzymatic as well as enzymatic components, the mitochondrial superoxide dismutase 2 (SOD2, $\mathrm{MnSOD}$ ) is a subject of particular interest, as it is located in the mitochondrial matrix where it represents the first line of antioxidant defense against superoxide anions produced as byproducts of oxidative phosphorylation. Superoxide dismutase 2 is a nuclear encoded tetrameric enzyme, which converts superoxide anion to hydrogen peroxide, which can further be removed by catalase and glutathione peroxidase. ${ }^{7}$ Superoxide anions are short lived, known to induce macromolecular damage—such as damage to DNA, proteins and lipids - and to react with other reactive oxygen/nitrogen species like nitric oxide to form highly

*Correspondence to: Karin Scharffetter-Kochanek;

Email: karin.scharffetter-kochanek@uniklinik-ulm.de

Submitted: 03/26/12; Revised: 07/27/12; Accepted: 08/13/12

http://dx.doi.org/10.4161/derm.21819 reactive peroxinitrite. Hydrogen peroxide, the product following dismutation of superoxide anion via SOD2, is more stable, can pass through membranes and has been shown to be an essential signaling molecule in a variety of signaling cascades and cellmatrix interactions. ${ }^{4,8,9}$ Mitochondrial-targeted overexpression of the hydrogen peroxide detoxifying enzyme catalase resulted in an extension of murine life span, showing for the first time the impact of ROS on mammalian longevity. ${ }^{10}$

In lower organisms, SOD2 was identified as part of a phylogenetically-conserved signaling pathway involved in longevity and resistance to oxidative stress. ${ }^{11}$ In humans, defined polymorphisms in the SOD2 gene correlate with longevity and heart failure in elderly, ${ }^{12,13}$ indicating a role of the SOD2 in human aging.

Among the histogenetically and functionally different tissues and compartments in the skin-which include the epidermis, the dermal connective tissue, adnexal structures like eccrine and apocrine glands, vessels and the subcutaneous tissue-the dermal connective tissue with its principal cellular component, the fibroblasts, plays a central role to study aging, as the incidence of aging-related disorders is high in connective tissue-rich organs.

\section{Adaptive Upregulation of SOD2 in Senescence and Aging}

Skin aging is characterized by atrophy, wrinkle formation, reduced tensile strength and impaired wound healing, with loss of the structural integrity and loss of the elastic and collagen fiber network due to dysfunctional fibroblasts. ${ }^{14,15}$ Dermal fibroblasts have therefore been used to model senescence in vitro, ${ }^{16-18}$ not only for the dermis, but also for other connective tissue rich organs. Skin aging, among other changes, is characterized by a loss of collagen type I, collagen type III among other matrix constituents, dysregulated fibroblast-matrix interactions and impaired fibroblast interactions with organ parenchyma, mainly with organ-specific epithelial cells and muscle. ${ }^{19-25}$ In human senescent skin, fibroblasts which develop a growth arrest, morphological and functional changes, increased ROS concentrations have been demonstrated in vitro and in vivo ${ }^{26-29}$ with an adaptive upregulation of the SOD2 on mRNA and protein level ${ }^{26,30,31}$ (Ferchiu et al., unpublished data) providing evidence for a common response phenotype of cellular senescence.

The upregulation of the SOD2 in human fibroblasts has also been shown to be induced in a paracrine mechanism either via UV-irradiation ${ }^{32,33}$ and/or the release of soluble factors 
(e.g., interleukin $1 \alpha$, interleukin $1 \beta$, and tumor necrosis factor $\alpha$ ) from keratinocytes. ${ }^{34}$ In this case, when SOD2 upregulation disturbs the balance of hydrogen peroxide $(\mathrm{H} 2 \mathrm{O} 2)$ level, the upregulation of $\mathrm{H} 2 \mathrm{O} 2$ detoxifying enzymes ensures that an accumulation of $\mathrm{H} 2 \mathrm{O} 2$ does not occur in the system. However, exclusive SOD2 overexpression in vitro has earlier been shown to result in enhanced $\mathrm{H} 2 \mathrm{O} 2$ concentration with activation of distinct signaling pathways and transcription factors, among them the heterodimeric AP-1 which enhance the transcription and activation of matrix-metalloproteinases among other genes and gene products. ${ }^{23}$ The family of matrix-metalloproteinases (MMP) so far consists of at least 20 members with distinct, partly-overlapping substrate specificities for extracellular matrix proteins of the skin. ${ }^{35,36}$ Imbalanced overexpression of SOD2 resulted in enhanced $\mathrm{H} 2 \mathrm{O} 2$ accumulation with the AP-1 dependent induction of interstitial collagenase (MMP-1) and degradation of interstitial collagen in the skin —a hallmark of skin aging. ${ }^{23,37,38}$

Although overexpression of SOD2 does not-or if so, only marginally does-increase life span in mice, ${ }^{39,40}$ reduced oxidative stress observed under caloric restriction seems to be due to SIRT3 mediated SOD2 activation..$^{41}$ Until now, caloric restriction represents the most robust intervention to extend life span and delay the onset of age related diseases in mice.

\section{Deficiency of SOD2 Induces Premature Aging}

Interestingly, there is indirect evidence that in aged skin, fibroblasts-both superoxide anion and $\mathrm{H}_{2} \mathrm{O}_{2}$-are increased (Ferchiu et al., unpublished data). ${ }^{29}$ To model the situation with an increase of superoxide anion, mice with deficiency of SOD2 were generated. Mice with a homozygous deficiency of SOD2 in all organs die within postnatal day 8 to 18 due to cardiomyopathy and neurodegeneration. ${ }^{42,43}$ Treatment with synthetic superoxide dismutase (SOD)-catalase mimetic (EUK) extends lifespan of mice with inactivated SOD2 by three-fold and attenuates mitochondrial defects. ${ }^{44}$ Corresponding to naturally-aged mouse skin, where the number of senescent cells increases ${ }^{45}$ and the mitochondrial activity decreases, constitutive lack of SOD2 correlates with an increase in senescence-associated $\beta$-galactosidase expression, impaired mitochondrial complex II activity and increased nuclear DNA damage in the skin. Cellular senescence in SOD2 nullizygous mice with decreased proliferation and increased terminal differentiation of keratinocytes may result in the observed thinning of the epidermis. ${ }^{25}$

Mice with a heterozygous deficiency of the SOD2 revealed an unchanged lifespan ${ }^{46}$ in spite of oxidative damage like lipid peroxidation, spontaneous apoptosis, ${ }^{47}$ endothelial dysfunction with impaired vasorelaxation and mtDNA damage. ${ }^{48}$ In the context of telomere dysfunction, heterozygous deficiency of SOD2 does not further accelerate aging. ${ }^{49}$

To study aging as consequence of mitochondrial oxidative stress, we therefore set out to generate mice with a conditional homozygous deficiency of SOD2 in fibroblasts resident in the connective tissue. Interestingly, due to a deficiency of SOD2 in fibroblasts in the connective tissue of virtually all organs, these mice gradually developed a progeroid aging phenotype in connective-tissue rich organs with severe skin atrophy, kyphosis, osteoporosis, muscle degeneration and finally a reduced life span (Fig. 1). In fact, a strong atrophy of the dermal connective tissue, the subcutaneous fat tissue and the muscle fibers of the panniculus carnosus were observed in skin sections of connective tissue specific SOD2 deficient mice. ${ }^{50}$ The architecture of the collagen fibers was severely disturbed compared with control skin with thin and loosely packed collagen bundles. Procollagen I was reduced in SOD2 deficient skin compared with control skin. Mitochondria from SOD2-deficient fibroblasts revealed severe morphological damage. SOD2 deficient fibroblasts showed a severe functional impairment with delay in organization of the surrounding collagen fibers, when seeded into three dimensional collagen matrices. No increase in the rate of apoptosis in skin sections of SOD2-deficient mutant mice, compared with the corresponding control skin sections of heterozygous and wild-type mice, was found, but a significant lower number of proliferating cells is found in mutant mouse skin, indicating that the atrophy is most probably due to a decrease in proliferation in the dermis as well as in the epidermis. We found the senescence marker p16INK4a significantly increased in mutant SOD2-deficient skin, and this is particularly relevant for human skin aging as we and others have previously shown that reactive oxygen species accumulate fibroblasts in skin in vitro and in vivo and, importantly, p16INK4a increases in human skin with age and represents a robust in vivo marker for aging. ${ }^{50-52}$

\section{Conclusion and Perspectives}

Superoxide anion concentrations increase in skin fibroblasts during senescence and skin aging (Ferchiu et al., unpublished data). We here provide evidence that the lack of connective tissue specific superoxide anion detoxification at least in part mimics the situation and leads to the installment of an oxidative damage induced senescence program with the upregulation of p16INK4a not only in the skin but in all connective tissue rich organs or the stroma surrounding the parenchyma, enabling further insights into the general mechanisms of cellular, tissue as well as organismal aging. This is particularly interesting in the light of a recent publication showing that the removal of p16INK4a expressing cells rescues skin as well as organismal aging. ${ }^{53}$ Further understanding of underlying mechanisms of ROS mediated premature aging will provide therapeutic approaches in pathological states to counteract accelerated skin aging in particular and organismal aging in general. It will be of clinical relevance to develop strategies to rebalance increased superoxide anions and most likely hydrogen peroxide concentrations in the connective tissue of the dermis and most likely of all organs to avoid the activation of tissue degradation and atrophy. The equipment of histogenetically distinct cells and tissues with antioxidant enzymes is not very well studied. Therefore it is dangerous to use systemic antioxidant approaches. Also it became clear that a mild oxidative stress by sport may delay aging which is abolished by the systemic application of $\mathrm{N}$-acetylcysteine. ${ }^{54}$ Therefore, it will be particularly interesting to target antioxidant rebalancing molecules to resident fibroblasts in the connective tissue. 


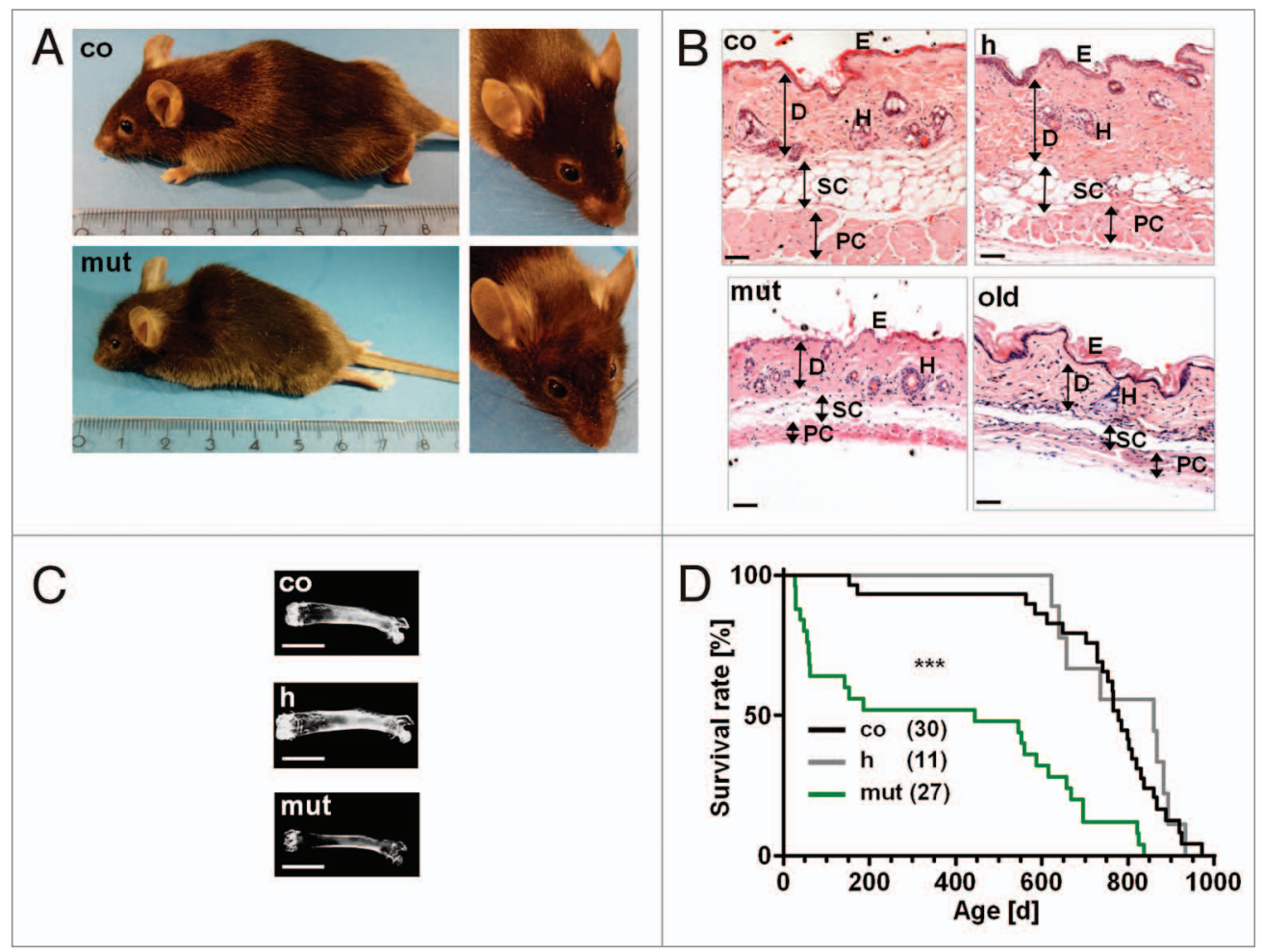

Figure 1. Accelerated aging phenotype in mice with conditional deficiency for mitochondrial superoxide dismutase in the connective tissue. (A) The mutant mice (mut) revealed kyphosis and a prominent progeroid forehead compared with littermates of SOD2 competent (co) mice at the age of $47 \mathrm{~d}$. The intrinsically aged control mice (co) of $900 \mathrm{~d}$ also exhibited incidence of kyphosis similar to mutant mice. (B) Representative hematoxylineosin stained sections of the skin from control (co), heterozygous (h), mutant (mut) and intrinsically aged control (old) mice. Mutant mice at an age of 6 weeks revealed a severe atrophy of the dermis, the subcutaneous fat tissue and the muscle fibers of the panniculus carnosus compared with SOD2 competent mice (co). Only minor changes in SOD2 heterozygous mice (h) were evident compared with SOD2 competent mice (co). Intrinsically aged control mice (old) of $900 \mathrm{~d}$ also show skin atrophy similar to mutant mice. E, epidermis; D, dermis; H, hair follicle; SC, subcutaneous fat tissue; PC, panniculus carnosus. Scale bars, $20 \mu \mathrm{m}$. (C) X-ray analysis from dissected femur bone of SOD2 competent mice (co), SOD2 heterozygous mice (h) and mutant mice (mut) revealed an osteoporosis-like phenotype in mutant mice. Scale bars, $0.5 \mathrm{~cm}$. (D) Significantly reduced survival time of mutant mice (median 444 d) compared with SOD2 competent control mice (median $784 \mathrm{~d}$ ) (*** $p<0.0001$, log-rank test stratified for gender). No statistically significant difference was found between SOD2 competent (co) and SOD2 heterozygous ( $h$ ) mice $(p=0.65)$. The maximal life span for mutant mice was $837 \mathrm{~d}$ compared with $971 \mathrm{~d}$ in SOD2 competent mice and $932 \mathrm{~d}$ in SOD2 heterozygous mice. Figure modified from Treiber et al., $2011 .{ }^{50}$

\section{Disclosure of Potential Conflicts of Interest}

No potential conflicts of interest were disclosed.

\section{Acknowledgments}

K.S.K. is supported by the German Research Foundation within the Clinical Research Group KFO142: "Cellular and
Molecular Mechanisms of Aging: From Mechanisms to Clinical Perspectives." M.W. and K.S.K. were supported by the European Union through the Integrated Project PROTEOMAGE (FP6518230). K.S.K. received a grant from the German Research Foundation within the Collaborative Research Centre SFB 497: "Signals and Signal Processing during Cellular Differentiation."

\section{References}

1. Harman D. Aging: a theory based on free radical and radiation chemistry. J Gerontol 1956; 11:298-300; PMID: 13332224

2. Balaban RS, Nemoto S, Finkel T. Mitochondria, oxidants, and aging. Cell 2005; 120:483-95; PMID:15734681; http://dx.doi.org/10.1016/j.cell.2005.02.001

3. Beckman KB, Ames BN. The free radical theory of aging matures. Physiol Rev 1998; 78:547-81; PMID:9562038

4. Finkel T. Signal transduction by reactive oxygen species. J Cell Biol 2011; 194:7-15; PMID:21746850; http:// dx.doi.org/10.1083/jcb.201102095

5. Sies H. Biochemistry of Oxidative Stress. Angew Chem Int Ed Engl 1986; 25:1058-71; http://dx.doi org/10.1002/anie.198610581

6. Sies H. Oxidative stress: oxidants and antioxidants. Exp Physiol 1997; 82:291-5; PMID:9129943
7. Miao L, St Clair DK. Regulation of superoxide dismutase genes: implications in disease. Free Radic Biol Med 2009; 47:344-56; PMID:19477268; http://dx.doi. org/10.1016/j.freeradbiomed.2009.05.018

8. Veal EA, Day AM, Morgan BA. Hydrogen peroxide sensing and signaling. Mol Cell 2007; 26:1-14; PMID:17434122; http://dx.doi.org/10.1016/j.molcel.2007.03.016

9. Werner E, Werb Z. Integrins engage mitochondrial function for signal transduction by a mechanism dependent on Rho GTPases. J Cell Biol 2002; 158:35768; PMID:12119354; http://dx.doi.org/10.1083/ jcb.200111028

10. Schriner SE, Linford NJ, Martin GM, Treuting P, Ogburn CE, Emond M, et al. Extension of murine life span by overexpression of catalase targeted to mitochondria. Science 2005; 308:1909-11; PMID:15879174; http://dx.doi.org/10.1126/science.1106653
11. Kops GJ, Dansen TB, Polderman PE, Saarloos I, Wirtz KW, Coffer PJ, et al. Forkhead transcription factor FOXO3a protects quiescent cells from oxidative stress. Nature 2002; 419:316-21; PMID:12239572; http:// dx.doi.org/10.1038/nature01036

12. Stessman J, Maaravi Y, Hammerman-Rozenberg R, Cohen A, Nemanov L, Gritsenko I, et al. Candidate genes associated with ageing and life expectancy in the Jerusalem longitudinal study. Mech Ageing Dev 2005; 126:333-9; PMID:15621215; http://dx.doi. org/10.1016/j.mad.2004.08.025

13. Valenti L, Conte D, Piperno A, Dongiovanni P, Fracanzani AL, Fraquelli M, et al. The mitochondrial superoxide dismutase A16V polymorphism in the cardiomyopathy associated with hereditary haemochromatosis. J Med Genet 2004; 41:946-50; PMID:15591282; http://dx.doi.org/10.1136/jmg.2004.019588 
14. Fisher GJ, Varani J, Voorhees JJ. Looking older: fibroblast collapse and therapeutic implications. Arch Dermatol 2008; 144:666-72; PMID:18490597; http:// dx.doi.org/10.1001/archderm.144.5.666

15. Quan T, Shao Y, He T, Voorhees JJ, Fisher GJ. Reduced expression of connective tissue growth factor (CTGF/ CCN2) mediates collagen loss in chronologically aged human skin. J Invest Dermatol 2010; 130:41524; PMID:19641518; http://dx.doi.org/10.1038/ jid.2009.224

16. Schneider LA, Wlaschek M, Scharffetter-Kochanek $\mathrm{K}$. [Skin aging--clinical aspects and pathogenesis]. J Dtsch Dermatol Ges 2003; 1:223-32; PMID:16285500; http://dx.doi.org/10.1046/j.1610-0387.2003.03515.x

17. Wlaschek M, Ma W, Jansen-Dürr P, ScharffetterKochanek K. Photoaging as a consequence of natural and therapeutic ultraviolet irradiation--studies on PUVA-induced senescence-like growth arrest of human dermal fibroblasts. Exp Gerontol 2003; 38:126570; PMID:14698806; http://dx.doi.org/10.1016/j. exger.2003.09.006

18. Cristofalo VJ, Pignolo RJ. Replicative senescence of human fibroblast-like cells in culture. Physiol Rev 1993; 73:617-38; PMID:8332640

19. Campisi J. Senescent cells, tumor suppression, and organismal aging: good citizens, bad neighbors. Cell 2005; 120:513-22; PMID:15734683; http://dx.doi. org/10.1016/j.cell.2005.02.003

20. Krtolica A, Campisi J. Cancer and aging: a model for the cancer promoting effects of the aging stroma. Int Biochem Cell Biol 2002; 34:1401-14; PMID:12200035; http://dx.doi.org/10.1016/S1357-2725(02)00053-5

21. Labat-Robert J, Robert L. The effect of cell-matrix interactions and aging on the malignant process. Adv Cancer Res 2007; 98:221-59; PMID:17433912; http://dx.doi. org/10.1016/S0065-230X(06)98007-5

22. Treiber N, Peters T, Sindrilaru A, Huber R, Kohn M, Menke A, et al. Overexpression of manganese superoxide dismutase in human dermal fibroblasts enhances the contraction of free floating collagen lattice: implications for ageing and hyperplastic scar formation. Arch Dermatol Res 2009; 301:273-87; PMID:19306099; http://dx.doi.org/10.1007/s00403-009-0935-9

23. Wenk J, Brenneisen P, Wlaschek M, Poswig A, Briviba K, Oberley TD, et al. Stable overexpression of manganese superoxide dismutase in mitochondria identifies hydrogen peroxide as a major oxidant in the AP-1-mediated induction of matrix-degrading metalloprotease-1. J Biol Chem 1999; 274:25869-76; PMID:10464329; http:// dx.doi.org/10.1074/jbc.274.36.25869

24. Wenk J, Schüller J, Hinrichs C, Syrovets T, Azoitei N, Podda M, et al. Overexpression of phospholipid-hydroperoxide glutathione peroxidase in human dermal fibroblasts abrogates UVA irradiation-induced expression of interstitial collagenase/matrix metalloproteinase-1 by suppression of phosphatidylcholine hydroperoxidemediated NFkappaB activation and interleukin- 6 release. J Biol Chem 2004; 279:45634-42; PMID:15308634; http://dx.doi.org/10.1074/jbc.M408893200

25. Velarde MC, Flynn JM, Day NU, Melov S, Campisi J. Mitochondrial oxidative stress caused by Sod 2 deficiency promotes cellular senescence and aging phenotypes in the skin. Aging (Albany NY) 2012; 4:3-12; PMID:22278880

26. Allen RG, Tresini M, Keogh BP, Doggett DL, Cristofalo VJ. Differences in electron transport potential, antioxidant defenses, and oxidant generation in young and senescent fetal lung fibroblasts (WI-38). J Cell Physiol 1999; 180:114-22; PMID:10362024; http://dx.doi.org/ $10.1002 /$ (S ICI) 1097 4652(199907)180:1<114::AID-JCP133.0.CO;2-0

27. Hütter E, Unterluggauer $H$, Uberall F, Schramek $H$, Jansen-Dürr P. Replicative senescence of human fibroblasts: the role of Ras-dependent signaling and oxidative stress. Exp Gerontol 2002; 37:1165-74; PMID:12470828; http://dx.doi.org/10.1016/S05315565(02)00136-5
28. Scharffetter-Kochanek K, Wlaschek M, Brenneisen P, Schauen M, Blaudschun R, Wenk J. UV-induced reactive oxygen species in photocarcinogenesis and photoaging. Biol Chem 1997; 378:1247-57; PMID:9426184

29. Shin $\mathrm{MH}$, Rhie GE, Kim YK, Park CH, Cho KH, $\mathrm{Kim} \mathrm{KH}$, et al. $\mathrm{H} 2 \mathrm{O} 2$ accumulation by catalase reduction changes MAP kinase signaling in aged human skin in vivo. J Invest Dermatol 2005; 125:221-9; PMID:16098030

30. Borlon C, Debacq-Chainiaux F, Hinrichs C, ScharffetterKochanek K, Toussaint O, Wlaschek M. The gene expression profile of psoralen plus UVA-induced premature senescence in skin fibroblasts resembles a combined DNA-damage and stress-induced cellular senescence response phenotype. Exp Gerontol 2007; 42:911 23; PMID:17574363; http://dx.doi.org/10.1016/j. exger.2007.04.009

31. Lu CY, Lee HC, Fahn HJ, Wei YH. Oxidative damage elicited by imbalance of free radical scavenging enzymes is associated with large-scale mtDNA deletions in aging human skin. Mutat Res 1999; 423:11-21; PMID:10029667; http://dx.doi.org/10.1016/S0027 5107(98)00220-6

32. Meewes C, Brenneisen P, Wenk J, Kuhr L, Ma W, Alikoski J, et al. Adaptive antioxidant response protect dermal fibroblasts from UVA-induced phototoxicity. Free Radic Biol Med 2001; 30:238-47; PMID:11165870 http://dx.doi.org/10.1016/S0891-5849(00)00463-9

33. Poswig A, Wenk J, Brenneisen P, Wlaschek M, Hommel C, Quel G, et al. Adaptive antioxidant response of manganese-superoxide dismutase following repetitive UVA irradiation. J Invest Dermatol 1999; 112:13-8 PMID:9886257; http://dx.doi.org/10.1046/j.15231747.1999.00465.x

34. Naderi-Hachtroudi L, Peters T, Brenneisen P, Meewes C, Hommel C, Razi-Wolf $\mathrm{Z}$, et al. Induction of manganese superoxide dismutase in human dermal fibroblasts: a UV-B-mediated paracrine mechanism with the release of epidermal interleukin 1 alpha, interleukin 1 beta, and tumor necrosis factor alpha. Arch Dermatol 2002; 138:1473-9; PMID:12437453; http://dx.doi. org/10.1001/archderm.138.11.1473

35. Hu J, Van den Steen PE, Sang QX, Opdenakker G. Matrix metalloproteinase inhibitors as therapy for inflammatory and vascular diseases. Nat Rev Drug Discov 2007; 6:480-98; PMID:17541420; http:// dx.doi.org/10.1038/nrd2308

36. Quan T, Qin Z, Xia W, Shao Y, Voorhees JJ, Fishe GJ. Matrix-degrading metalloproteinases in photoaging. J Investig Dermatol Symp Proc 2009; 14:20 4; PMID:19675548; http://dx.doi.org/10.1038/ jidsymp. 2009.8

37. Fisher GJ, Quan T, Purohit T, Shao Y, Cho MK, He T, et al. Collagen fragmentation promotes oxidative stress and elevates matrix metalloproteinase- 1 in fibroblasts in aged human skin. Am J Pathol 2009; 174:10114; PMID:19116368; http://dx.doi.org/10.2353/ ajpath.2009.080599

38. Ibrahim W, Lee US, Yen HC, St Clair DK, Chow CK. Antioxidant and oxidative status in tissues of manganese superoxide dismutase transgenic mice. Free Radic Biol Med 2000; 28:397-402; PMID:10699751; http:/ dx.doi.org/10.1016/S0891-5849(99)00253-1

39. Hu D, Cao P, Thiels E, Chu CT, Wu GY, Oury TD, et al. Hippocampal long-term potentiation, memory, and longevity in mice that overexpress mitochondrial superoxide dismutase. Neurobiol Learn Mem 2007; 87:372 84; PMID:17129739; http://dx.doi.org/10.1016/j. $\mathrm{nlm} .2006 .10 .003$

40. Jang YC, Pérez VI, Song W, Lustgarten MS, Salmon $\mathrm{AB}$, Mele J, et al. Overexpression of Mn superoxide dismutase does not increase life span in mice. J Gerontol A Biol Sci Med Sci 2009; 64:1114-25; PMID:19633237; http://dx.doi.org/10.1093/gerona/glp100

41. Qiu X, Brown K, Hirschey MD, Verdin E, Chen D. Calorie restriction reduces oxidative stress by SIRT3mediated SOD2 activation. Cell Metab 2010; 12:6627; PMID:21109198; http://dx.doi.org/10.1016/j. cmet.2010.11.015
42. Lebovitz RM, Zhang H, Vogel H, Cartwright J Jr., Dionne L, Lu N, et al. Neurodegeneration, myocardial injury, and perinatal death in mitochondrial superoxide dismutase-deficient mice. Proc Natl Acad Sci U S A 1996; 93:9782-7; PMID:8790408; http://dx.doi org/10.1073/pnas.93.18.9782

43. Li Y, Huang TT, Carlson EJ, Melov S, Ursell PC, Olson JL, et al. Dilated cardiomyopathy and neonatal lethality in mutant mice lacking manganese superoxide dismutase. Nat Genet 1995; 11:376-81; PMID:7493016; http://dx.doi.org/10.1038/ng1295-376

44. Melov S, Doctrow SR, Schneider JA, Haberson J, Patel M, Coskun PE, et al. Lifespan extension and rescue of spongiform encephalopathy in superoxide dismutase 2 nullizygous mice treated with superoxide dismutase-catalase mimetics. J Neurosci 2001; 21:8348 53; PMID:11606622

45. Wang C, Jurk D, Maddick M, Nelson G, Martin-Ruiz $\mathrm{C}$, von Zglinicki T. DNA damage response and cellular senescence in tissues of aging mice. Aging Cell 2009; 8:311-23; PMID:19627270; http://dx.doi.org/10.1111/ j.1474-9726.2009.00481.x

46. Van Remmen H, Ikeno $\mathrm{Y}$, Hamilton $\mathrm{M}$, Pahlavan $\mathrm{M}$, Wolf N, Thorpe SR, et al. Life-long reduction in MnSOD activity results in increased DNA damage and higher incidence of cancer but does not accelerate aging. Physiol Genomics 2003; 16:29-37; PMID:14679299; http://dx.doi.org/10.1152/physiolgenomics.00122.2003

47. Strassburger M, Bloch W, Sulyok S, Schüller J, Keist AF, Schmidt A, et al. Heterozygous deficiency of manganese superoxide dismutase results in severe lipid peroxidation and spontaneous apoptosis in murine myocardium in vivo. Free Radic Biol Med 2005; 38:1458-70 PMID:15890620; http://dx.doi.org/10.1016/j.freeradbiomed.2005.02.009

48. Wenzel P, Schuhmacher S, Kienhöfer J, Müller J, Hortmann M, Oelze M, et al. Manganese superoxide dismutase and aldehyde dehydrogenase deficiency increase mitochondrial oxidative stress and aggravate agedependent vascular dysfunction. Cardiovasc Res 2008; 80:280-9; PMID:18596060; http://dx.doi.org/10.1093/ $\mathrm{cvr} / \mathrm{cvn} 182$

49. Guachalla LM, Ju Z, Koziel R, von Figura G, Song Z, Fusser M, et al. Sod2 haploinsufficiency does not accelerate aging of telomere dysfunctional mice. Aging (Albany NY) 2009; 1:303-15; PMID:20195488

50. Treiber N, Maity P, Singh K, Kohn M, Keist AF, Ferchiu $\mathrm{F}$, et al. Accelerated aging phenotype in mice with conditional deficiency for mitochondrial superoxide dismutase in the connective tissue. Aging Cell 2011; 10:239-54; PMID:21108731; http://dx.doi.org/10.1111/j.14749726.2010.00658.x

51. Ressler S, Bartkova J, Niederegger H, Bartek J, Scharffetter-Kochanek K, Jansen-Dürr P, et al. p16INK4A is a robust in vivo biomarker of cellular aging in human skin. Aging Cell 2006; 5:379-89; PMID:16911562; http://dx.doi.org/10.1111/j.14749726.2006.00231.x

52. Krishnamurthy J, Torrice C, Ramsey MR, Kovalev GI, Al-Regaiey K, Su L, et al. Ink4a/Arf expression is a biomarker of aging. J Clin Invest 2004; 114:1299-307; PMID:15520862

53. Baker DJ, Wijshake T, Tchkonia T, LeBrasseur NK Childs BG, van de Sluis B, et al. Clearance of p16Ink4apositive senescent cells delays ageing-associated disorders. Nature 2011; 479:232-6; PMID:22048312; http:// dx.doi.org/10.1038/nature10600

54. Ristow M, Zarse K, Oberbach A, Klöting N, Birringer M, Kiehntopf M, et al. Antioxidants prevent health-promoting effects of physical exercise in humans. Proc Natl Acad Sci U S A 2009; 106:8665-70; PMID:19433800; http://dx.doi.org/10.1073/pnas.0903485106 